\title{
Echocardiographic assessment of left ventricular filling characteristics after mitral valve replacement with the St Jude medical prosthesis
}

\author{
M ST JOHN SUTTON, R ROUDAUT, P OLDERSHAW, H BRICAUD \\ From the Department of Cardiology, Brompton Hospital, London; and \\ Hôpital Cardiologique, Bordeaux, Pessec, France
}

SUMMARY The major cause of late mortality and morbidity after prosthetic valve replacement is thromboembolism. The nidus for initiation of thrombus for mation has been blood metal interfaces, and a new valve-the St Jude prosthesis-has therefore been developed without any metal components. We have assessed echocardiographically in 27 patients the effects of this valve on left ventricular filling characteristics when inserted in the mitral position and compared the findings with those in patients having mitral valve replacement with Starr-Edwards or Björk-Shiley prostheses and with those in patients undergoing repair of the native mitral valve. Echocardiograms were recorded and digitised. Measurements were made of the peak rate of increase of dimension $(\mathrm{dD} / \mathrm{dt})$ and duration of rapid filling. Values for the St Jude valve were $13.2 \pm 3.4 \mathrm{~cm} / \mathrm{s}$ and $160 \pm 40 \mathrm{~ms}$, respectively. The peak rate of $\mathrm{dD} / \mathrm{dt}$ increase was significantly greater than with either the Björk-Shiley valve or the Starr-Edwards valve and was comparable with findings in mitral valve repair. The duration of the rapid filling phase was not significantly different from control values but was less than that of the Starr-Edwards valve. This study indicates that the new St Jude medical valve is less obstructive than either the Björk-Shiley or Starr-Edwards prostheses. This together with its low thrombogenicity suggests that further trials of this new valve should be undertaken.

Since the introduction of valve replacement, the search has continued for a prosthesis which is durable, non-thrombogenic, and which approximates haemodynamically to the native valve. The combination of these three factors in one valve has so far defied production. ${ }^{1}$ Though the incidence of thromboembolism with effective anticoagulation is low, there is no significant difference between ball and cage ${ }^{2}$ and tilting disc prostheses in this respect. ${ }^{3}$ Valve areas and transvalvular gradients, however, have been consistently lower in the latter. ${ }^{4}$ Before the introduction of new prostheses, it is important to evaluate their usefulness in man carefully, remembering previous high failure and complication rates. ${ }^{6}$ The St Jude medical valve is at present undergoing preliminary study..$^{7-9}$ To assess the effect of this prosthesis on left ventricular filling characteristics when inserted in the mitral position, we determined the peak velocity of left ventricular wall movement in early diastole and the duration of the rapid filling phase of the left ventricle and Received for publication 22 October 1980 compared these measurements with results obtained from patients with Björk-Shiley and Starr-Edwards mitral prostheses, and with repair of the native mitral valve. ${ }^{10}$

\section{Patients}

Studies were performed on 27 patients from Hôpital Cardiologique, Bordeaux, Pessec, and Brompton Hospital, London. Thirteen of these patients were female and 14 male, ranging in age from 13 to 67 years (mean 47). All underwent mitral valve replacement with the St Jude medical prosthesis (size 29 or $31 \mathrm{~mm}$ ) for rheumatic or degenerative mitral valve disease. Echocardiograms were obtained from two weeks to 14 months postoperatively (median two months). The results were compared with those from patients previously reported, 30 of whom had undergone mitral valve replacement with/Starr-Edwards (size 3 or 4), 30 with Björk-Shiley (size 29 or $31 \mathrm{~mm}$ ) prostheses, and 30 who had had mitral valve repair. All four patient 
groups had similar sex distribution, age range, and pathophysiology.

\section{Methods}

Echocardiograms were obtained using either an Ekoline 20 Ultrasonoscope or Cambridge Instruments equipment. Recordings were made using a strip-chart recorder at paper speeds of 50 to $100 \mathrm{~mm} / \mathrm{s}$ with simultaneous electrocardiograms. Echoes from the endocardial surface of the left side of the septum and the posterior left ventricular wall were recorded from just below the level of the mitral prosthesis. Measurements were made only in patients in whom clear continuous echoes were obtained simultaneously from the left side of the septum and the posterior wall endocardium throughout the cardiac cycle.

Echocardiograms were digitised as previously described $^{11}$ on a Summagraphics digitising table and processed by a Prime 300 computing system. Three beats from each echocardiogram were digitised, since the coefficient of variation for diastolic measurements was approximately 10 per cent (Table 1).

Instantaneous left ventricular dimension (D), and its peak rate of increase during diastole $(\mathrm{dD} / \mathrm{dt})$ were derived from the echocardiograms. Left ventricular filling characteristics were assessed using the peak rate of increase of left ventricular dimension in diastole, and also the interval between minimum left ventricular dimension and the time at which peak $\mathrm{dD} / \mathrm{dt}$ had fallen to 20 per cent of its peak value (that is the duration of the rapid filling phase). ${ }^{11} 12$ Septal excursion from end-diastole to the time of minimum dimension (that is when $\mathrm{dD} / \mathrm{dt}=$ zero) was also measured to assess the effect of septal motion on peak left ventricular cavity filling rate. Patients were then grouped according to whether septal movement was greater than $5 \mathrm{~mm}$,

Table 1 Postoperative left ventricular cavity dimensions and dynamics in 27 patients with St fude mitral valve replacements

\begin{tabular}{|c|c|c|c|c|}
\hline & Mean & $\begin{array}{l}\text { Between } \\
\text { patient } \\
\text { standard } \\
\text { deviation }\end{array}$ & $\begin{array}{l}\text { Within- } \\
\text { patient } \\
\text { standard } \\
\text { deviation }\end{array}$ & $\begin{array}{l}\text { Coefficient } \\
\text { of } \\
\text { variation } \\
(\%)\end{array}$ \\
\hline \multirow{6}{*}{$\begin{array}{l}\text { End-diastolic dimension }(\mathrm{cm}) \\
\text { End-systolic dimension }(\mathrm{cm}) \\
\text { Peak VCF/s } \\
\text { Peak rate of dimension } \\
\text { increase } \mathrm{cm} / \mathrm{s} \\
\text { Rapid filling period (ms) }\end{array}$} & $5 \cdot 1$ & $1 \cdot 1$ & 0.79 & 15 \\
\hline & 3.4 & $1 \cdot 2$ & 0.72 & 19 \\
\hline & $2 \cdot 5$ & 0.8 & 0.58 & 30 \\
\hline & & & & \\
\hline & $13 \cdot 2$ & 3.4 & $1 \cdot 2$ & 10 \\
\hline & 160 & 40 & 23 & 11 \\
\hline
\end{tabular}

Table 2 Values for peak $d D / d t$ and duration of rapid filling period in normals, patients with mitral valve repair, and mitral valve replacement with St fude, Björk-Shiley, and Starr-Edwards prostheses

\begin{tabular}{|c|c|c|c|}
\hline Valve & No. & $\begin{array}{l}P k d D / d t \\
(\mathrm{~cm} / \mathrm{s})\end{array}$ & $\begin{array}{l}\text { Duration of rapid } \\
\text { filling period } \\
\text { (ms) }\end{array}$ \\
\hline Normal & 14 & $16 \pm 3 \cdot 2$ & $160 \pm 50$ \\
\hline Mitral repair & 30 & $14 \cdot 4 \pm 5 \cdot 0^{\star}$ & $170 \pm 50$ \\
\hline $\begin{array}{l}\text { St Jude medical } \\
\text { (size } 29 \text { or } 31 \mathrm{~mm} \text { ) }\end{array}$ & 27 & $13 \cdot 2 \pm 3 \cdot 4^{\star} \dagger$ & $160 \pm 40 t$ \\
\hline $\begin{array}{l}\text { Björk-Shiley } \\
\text { (size } 29 \text { or } 31 \mathrm{~mm} \text { ) }\end{array}$ & 30 & $10 \cdot 5 \pm 4 \cdot 2^{\star}$ & $180 \pm 80$ \\
\hline $\begin{array}{l}\text { Starr-Edwards } \\
\quad(\text { size } 3 \text { or } 4)\end{array}$ & 30 & $7 \cdot 4 \pm 3 \cdot 0^{\star}$ & $295 \pm 110^{\star}$ \\
\hline
\end{tabular}

${ }^{*} \mathrm{p}<0.01$ compared with normal.

tp $<0.01$ compared with Björk-Shiley and/or Starr-Edwards. $\star+\mathrm{p}<0.01$ compared with Starr-Edwards.

Results mean + SD

0 to $+5 \mathrm{~mm}$ (normal), or 0 to $-5 \mathrm{~mm}$ (reversed).

The statistical significance of differences between means was assessed by Student's $t$ test.

\section{Results}

Left ventricular cavity size at end-diastole and endsystole, peak rate of increase in left ventricular dimension in diastole $(\mathrm{dD} / \mathrm{dt} \max )$, duration of the rapid left ventricular filling period, and peak VCF are shown in Table 1 . The peak rate of $\mathrm{dD} / \mathrm{dt}$ increase in diastole in the patients with St Jude medical prostheses was significantly greater than in those with either the Björk-Shiley $(p<0.01)$ or the Starr-Edwards prostheses $(p<0.01)$ and was comparable to that in patients with mitral valve repair (Table 2). The duration of the rapid filling period in patients with the St Jude valve was normal and significantly different from the Starr-Edwards valve $(p<0.01)$. The effect of the St Jude prosthesis on left ventricular filling characteristics thus closely approximates to that of mitral valve repair, indicating that it is less obstructive than either the Björk-Shiley or the Starr-Edwards valve.

Septal motion in patients after mitral valve replacement with the St Jude prosthesis returned to normal within two weeks in $20(74 \%)$ of the 27 patients, whereas this did not occur in patients with normally functioning Starr-Edwards or BjörkShiley prostheses; indeed when it was present in the latter it was frequently caused by a paravalvar leak. ${ }^{13}$ Return to normal septal motion was an occasional late finding $(12 \%)$ after mitral valve repair.

The effect of septal motion on peak left ven- 
tricular cavity filling rate was assessed at least two weeks after operation by correlating septal excursion with $\mathrm{dD} / \mathrm{dt}$. Patients were allocated to one of three groups: (1) septal movement greater than $5 \mathrm{~mm}$, (2) 0 to $+5 \mathrm{~mm}$, (3) 0 to $-5 \mathrm{~mm}$. The mean peak $\mathrm{dD} / \mathrm{dt}$ values for the three groups were (mean $\pm \mathrm{SD}$ ) $16.3 \pm 3.3, \quad 12.5 \pm 3.6$, and $12.1 \pm 3.3 \mathrm{~cm} / \mathrm{s}$, respectively. Patients with a septal excursion of more than $5 \mathrm{~mm}$ had a mean peak $\mathrm{dD} / \mathrm{dt}$ significantly greater $(p<0.05)$ than patients with a septal excursion of 0 to $+5 \mathrm{~mm}$ or 0 to $-5 \mathrm{~mm}$, indicating that septal motion, if large, may affect peak left ventricular filling rate. There was no significant difference in peak rate of left ventricular dimension increase between the groups of patients with septal excursion of 0 to $+5 \mathrm{~mm}$ and 0 to $-5 \mathrm{~mm}$. There was no significant difference in the duration of the rapid filling phase between patients with septal movement of 0 to $-5 \mathrm{~mm}, 0$ to $+5 \mathrm{~mm}$, or $>5 \mathrm{~mm}$ $(160 \pm 30 \mathrm{~ms}, 160 \pm 40 \mathrm{~ms}$, and $170 \pm 40 \mathrm{~ms}$, respectively).

\section{Discussion}

Our study was designed to examine the effect of the St Jude medical valve inserted in the mitral position on left ventricular wall motion during ventricular filling and to compare this with that of the Björk-Shiley and Starr-Edwards prostheses and with that of mitral valve repair. The non-invasive echocardiographic methods have previously been validated against angiographic measurements. ${ }^{12}$

Peak rates of increase in left ventricular dimension in patients with St Jude valves were similar to those in patients with mitral valve repair, but significantly greater than those in patients with Björk-Shiley or Starr-Edwards prostheses, suggesting that the St Jude valve was less obstructive to the flow of blood from the left atrium to the left ventricle, which is consistent with its lower transvalve gradient. ${ }^{7}$ The duration of the rapid diastolic filling period in patients with the St Jude valve was normal, similar to that occurring in patients with mitral valve repair and replacement with the Björk-Shiley valve, but significantly shorter than that in those with the Starr-Edwards prosthesis. Thus, the effects of the St Jude valve on the pattern of left ventricular wall motion during filling were indistinguishable from those found after mitral valve repair, an operation possible in only a minority of patients and with a high failure rate. A further manifestation of the difference between patients with the St Jude valve and those with the Björk-Shiley or Starr-Edwards prostheses was that septal motion returned to normal in $\mathbf{7 4}$ per cent of patients within two weeks of operation, in the absence of either clinically detectable or radiologically evident para-prosthetic regurgitation. Septal motion may return to normal late after mitral valve repair, but does so much less commonly after mitral valve replacement with the Björk-Shiley or Starr-Edwards valves unless paraprosthetic regurgitation is present. ${ }^{13}$ The reasons for this difference are not clear. It alone does not account for the greater peak rate of left ventricular filling, and the duration of rapid filling to which this is reciprocally related, since normal septal motion was present in only 20 of the 27 patients with St Jude valves; in addition the peak rate of left ventricular filling can be normal even when septal motion is completely reversed. ${ }^{14}$ In the six patients with septal excursion of $>5 \mathrm{~mm}$, however, there was a significant increase in peak left ventricular filling rate, indicating a contributory effect of septal motion on the filling pattern.

Other studies on the St Jude valve have also been encouraging. Thromboembolism remains the major cause of late mortality and morbidity after mitral replacement even with careful control of anticoagulation. ${ }^{15}$ Radical variation in prosthetic valve design has not so far significantly influenced this, since thrombus has usually formed initially on the atrial side of the prosthesis around the metal struts of the cage or the hinges of the tilting disc. ${ }^{16}$ Since the nidus for initiation of thrombus formation ${ }^{16}$ has been the blood-metal interface, the St Jude medical prosthesis has been developed without any metal components. Early reports suggest that its thrombogenicity is low. ${ }^{8}$

Haemodynamic assessment of St Jude prostheses in man at rest and during exercise has shown them to have smaller transvalvar gradients than porcine xenografts. ${ }^{9}$ It is likely that this is the result in part of there being no central occluder, and of the two tilting discs with opening angles of $90^{\circ}$ compared with the $60^{\circ}$ of the Björk-Shiley valve, thereby permitting a more central laminar flow. In addition, the haemolytic effect of the new prosthesis is small, and no case of severe anaemia has yet been reported. ${ }^{8}$

This echocardiographic assessment of the effects of mitral valve replacement with the St Jude medical prosthesis on left ventricular filling characteristics suggests that it is less obstructive than either the Björk-Shiley or the Starr-Edwards valves and these findings are consistent with both in vivo and in vitro haemodynamic data. These results, in conjunction with the other attributes of nonthrombogenicity, low transvalvar gradients, and negligible haemolytic properties suggest that there should be further trials of this new mechanical prosthesis in man. 


\section{References}

1 St John Sutton MG, Miller GAH, Oldershaw PJ, Paneth M. Anticoagulants and the Björk. Shiley prosthesis. Experience of 390 patients. Br Heart $\mathcal{F}$ 1978; 40: 558-52.

2 Bonchek LI, Starr A. Ball valve prostheses: current appraisal of late results. $A m$ f Cardiol 1975; 35: 843-54.

3 Björk VO, Henze A. Ten years' experience with the Björk-Shiley tilting disc valve. $\mathcal{f}$ Thorac Cardiovasc Surg 1979; 78: 331-42.

4 Björk VO. A new tilting disc valve prosthesis. Scand $\mathcal{F}$ Thorac Cardiovasc Surg 1969; 3: 1-10.

5 Björk VO, Holmgren A, Olin C, Ovenfors GO. Clinical and haemodynamic results of aortic valve replacement with Björk-Shiley tilting disc valve prosthesis. Scand $\mathcal{F}$ Thorac Cardiovasc Surg 1971; 5: 177-91.

6 Braunwald NS, Detmer DE. A critical analysis of the status of prosthetic valves and homografts. Prog Cardiovasc Dis 1968; 11: 113-32.

7 Emery RW, Nicoloff DM. St Jude medical cardiac valve prosthesis-in vivo studies. $f$ Thorac Cardiovasc Surg 1979; 78: 269-76.

8 Emery RW, Mettler E, Nicoloff DM. A new cardiac prosthesis: the St Jude Medical cardiac valve-in vivo results. Circulation 1979; 59 and 60, suppl I: 48-54.

9 Gray R, Chaux A. Matloff J, Raymond M. Early post operative hemodynamic comparison of St. Jude cardiac prostheses and porchine xenografts, at rest and with stress (abstract). Circulation 1979; 59 \& 60, suppl II: 222.

10 St John Sutton MG, Traill TA, Ghafour AS,
Brown DJ, Gibson DG. Echocardiographic assessment of left ventricular filling after mitral valve surgery. Br Heart $\mathcal{f}$ 1977; 39: 1283-91.

11 Gibson DG, Brown DJ. Measurement of instantaneous left ventricular dimension and filling rate in man, using echocardiography. Br Heart $\mathcal{f}$ 1973; 35: $1141-9$.

12 Gibson DG, Brown DJ. Measurement of peak rates of left ventricular wall movement in man; comparison of echocardiography with angiography. Br Heart f 1975; 37: 677-83.

13 Miller HC, Gibson DG, Stephens JD. Role of echocardiography and phonocardiography in diagnosis of mitral paraprosthetic regurgitation with Starr-Edwards prostheses. $\mathrm{Br}$ Heart $\mathcal{f} 1973 ; 35$ : 1217-25.

14 St. John Sutton MG, Tajik AJ, Mercier LA, Seward JB, Giuliani ER, Ritman EL. Assessment of left ventricular function in secundum atrial septal defect by computer analysis of the M-mode echocardiogram. Circulation 1979; 60: 1082-90.

15 MacManus Q, Grunkemeier G, Thomas D, Lambert LE, Starr A. The Starr-Edwards model 6000 valve. A fifteen-year follow up of the first successful mitral prosthesis. Circulation 56: 623-631.

16 Lee ME, Murakami T, Stanczewski B, Parmeggiani A, Srinivasan S, Sawyer PN. Etiology of thrombus formation on prosthetic metal heart valves. The role of spontaneous in vivo interfacial potentials and their measurements. F Thorac Cardiovasc Surg 1972; 63: 809-19.

Requests for reprints to $\mathrm{Dr} P \mathrm{~J}$ Oldershaw, Brompton Hospital, Fulham Road, London SW3 $6 \mathrm{HP}$. 